\title{
DYNAMIC FATIGUE RESISTANCE AND MARGINAL LEAKAGE OF ENDOCROWNS FABRICATED WITH TWO DIFFERENT CAD/CAM CERAMIC MATERIALS
}

\author{
Mohamed Abdel-Aziz* and Hanaa Nassar**
}

\begin{abstract}
Aim: To assess the effect of two CAD/CAM monolithic restorative materials on the fracture resistance of endocrowns subjected to dynamic fatigue loading. Also, the effect of surface pretreatment of each material on microleakage was studied.

Materials and Methods: Twenty-eight freshly extracted human mandibular first molars were collected and access cavity for each molar was performed for endodontic treatment. All excess gutta-percha was removed from the pulp chamber $1 \mathrm{~mm}$ below the orifice of each canal and filled to the level of pulp chamber using flowable resin composite. All teeth samples were prepared to receive endocrown restorations. Samples were randomly divided into two groups $(n=14)$ according to the type of endocrown $\mathrm{CAD} / \mathrm{CAM}$ monolithic restoration materials; lithium disilicate (IPS E-max CAD) and resin hybrid ceramic (SHOFU Block HC). CAD/CAM endocrown restorations were fabricated using CEREC AC system. Surface pretreatment protocol specific for each type of material was done. Then, endocrowns were cemented to their corresponding teeth samples with dualcured adhesive resin cement. All specimens were subjected to thermocycling with 5000 cycles, at $5^{\circ}$ and $55^{\circ} \mathrm{C}$. and 25 seconds dwell time. Each group was then subdivided into two equal subgroups $(n=7)$ according to the type of test used in the study; dynamic fatigue test and microleakage test. The results were collected and statistically analyzed using a student t-test to verify the statistical differences between both groups. Correlation between leakage and dynamic fatigue failure was found by Pearson linear correlation. P values $<0.05$ were statistically significant in all tests.
\end{abstract}

Results: Shofu HC (SH) group recorded a higher significant difference in the mean \pm SD value of dynamic fatigue failure load $(1005.02 \pm 100.25 \mathrm{~N})$ and cycles $(41001 \pm 3196$ cycles) than E.max CAD (LD) group with mean \pm SD value $(881.76 \pm 52.39 \mathrm{~N})$ and $(36088 \pm 2619$ cycles $)$ as indicated by the student t-test $(\mathrm{P}<0.05)$. While LD group recorded a higher significant difference mean $\pm \mathrm{SD}$ value of leakage $(122.87 \pm 15.84 \mu \mathrm{m})$ than the $\mathrm{SH}$ group's mean \pm SD value $(102.04 \pm 11.20 \mu \mathrm{m})$ as indicated by the student $\mathrm{t}$-test $(\mathrm{P}=0.0149<0.05)$. There was an inverse correlation between microleakage and dynamic fatigue failure load of the tested groups as indicated by Pearson linear correlation.

Conclusions: Endocrowns made of Shofu HC resin-hybrid ceramic showed higher dynamic fatigue resistance load and lower microleakage compared with that made of lithium disilicate glass-ceramic E.max CAD. Shofu HC Hybrid CAD/CAM blocks can be considered as a promising alternative material to lithium disilicate blocks in the restoration of endocrowns.

KEYWORDS: Endodontically treated teeth, CAD/CAM, lithium disilicate, resin-hybrid ceramic, endocrowns, dynamic fatigue load, microleakage.

\footnotetext{
* Associate Professor, Fixed Prosthodontics Department, Faculty of Dental Surgery, Ahram Canadian University.

** Lecturer, Fixed Prosthodontics Department, Faculty of Dental Surgery, Ahram Canadian University.
} 


\section{INTRODUCTION}

Restoration of endodontically treated teeth is a constant clinical challenge in dental practice owing to the excessive tooth structure loss either by caries, tooth fracture or during endodontic treatment itself. Over the past two decades, endocrown was accepted as a more conservative alternative to post-and-core supported crowns for restoration of endodontically treated teeth with satisfactory long-term survival rates in selected patients and with standardized clinical protocol for preparation and bonding (1). Endocrown is a monoblock coronal restoration, first proposed by Bindl and Mörmann that is retained macro-mechanically inside the pulp chamber as well as micro-mechanically through bonding to the remaining coronal tooth structure ${ }^{(2)}$.

Chair side digital CAD/CAM technology provides efficient and precise CAD/CAM restorations in terms of marginal accuracy and occlusal morphology ${ }^{(4)}$. Moreover, it enables same day delivery of high-quality monolithic CAD/CAM ceramic restoration to the patient ${ }^{(5)}$. Glass-ceramics and resin hybrid ceramics are among the monolithic CAD/CAM materials that have been commonly used for the construction of indirect endocrown restorations $^{(6,7)}$.

E-max CAD is a monolithic lithium disilicate glass-ceramic that delivers a high esthetic and biocompatible restoration. Furthermore, it exhibits high mechanical properties such as high flexural strength and high elastic modulus ${ }^{(8)}$. However, it is stiff, hard, and brittle which may affect its durability and machinability ${ }^{(4)}$.

$\mathrm{CAD} / \mathrm{CAM}$ composite hybrid ceramic materials have recently developed with improved physical and mechanical characteristics by changing their manufacturing methods, through high temperature and/or high-pressure new polymerization mode, and structure (glass ceramic networks) ${ }^{(9)}$. CAD/CAM hybrid ceramics reduce wear to the opposing tooth structure clinically due to less hardness and stiffness compared to monolithic ceramics. Furthermore, they are less brittle than ceramics ${ }^{(10)}$, easily milled and fabricated with less chipping and better marginal quality ${ }^{(11)}$.

Two main groups of CAD/CAM resin hybrid ceramic blocks can be recognized according to their microstructural geometry: a) polymerinfiltrated ceramic networks (PICN) which are high temperature and high pressure polymerized (e.g; Vita Enamic) and b) resin with dispersed fillers which are high temperature polymerized (e.g; Lava ultimate, Shofu Block HC) ${ }^{(9)}$. Shofu Block HC is a resin hybrid ceramic block containing urethane dimethacrylate (UDMA), triethylene glycol dimethacrylate (TEGDMA) as a resin matrix with silica, zirconia, and barium glass as dispersed filler particles ${ }^{(12)}$. The manufacturer claims that Shofu Block HC as a CAD/CAM resin hybrid ceramic material provides high esthetic results, fast milling and polishing, and high flexural strength together with high elasticity which allows stress absorption. Moreover, as claimed by the manufacturer, HC primer bonding system provides proper surface pretreatment of the restoration for reliable bonding with resin cement.

Previous studies reported that the improved bond strength of $\mathrm{CAD} / \mathrm{CAM}$ restorations to resin cement increased their fracture resistance and maintained their marginal integrity as well ${ }^{(13,14)}$. For endodontically treated tooth, the ideal restoration should preserve the remaining tooth structure without any marginal leakage together with proper function and esthetics ${ }^{(15)}$.

Therefore, the purpose of this in-vitro study was to compare the dynamic fatigue loading on the fracture resistance of endodontically treated teeth restored with two different endocrown CAD/CAM ceramic materials. Comparing the effect of surface pre-treatments of each material to the bonded surfaces on microleakage was also studied. The null hypothesis was that the two different endocrown CAD/CAM ceramic materials with their surface pretreatments for bonding would not differ in fatigue resistance, and microleakage. 


\section{MATERIALS AND METHODS}

\section{Specimen preparation}

The study was approved by the research ethics committee of the Faculty of Dentistry, Ahram Canadian University, (approval \#FDACUREC/01022021/AM). Twenty-eight freshly extracted human mandibular first molars were collected from oral surgery department. The inclusion criteria were complete root formation, absence of carious lesions, Absence of cracks, or visible root fractures. The size of the selected molars was measured by digital caliper (Mitutoyo IP 65, Kawasaki, Japan) to verify that they all were nearly similar mesiodistal and buccolingual dimensions at cemento-enamel junction with maximum deviation in dimension of $10 \%$. All teeth were ultrasonically cleaned to remove the external debris then stored at room temperature in distilled water with $0.1 \%$ thymol disinfectant (Caelo, Hilden, Germany) till use.

All specimen preparation, endodontic procedure and endocrown preparation steps for each molar were performed by the same operator using the exact same sequence for each to ensure standardization of the procedures.

\section{Endodontic procedure}

For each tooth, round carbide bur in a high-speed contra-angle was used for access cavity to the pulp chamber following its respective morphology. The radicular pulp tissue was extirpated by endodontic reamer. Standardized crown-down technique root canal preparation was performed by electric motor (X-Smart Dentsply Maillefer, Ballaigues, Switzerland), using Protaper system (DentsplyMaillefer; Ballaigues, Switzerland). For mesial canals, F2 files were chosen as master files while F3 files were chosen for distal canals. Irrigation was done with $1 \%$ sodium hypochlorite for 10 seconds between each file.

After final canal irrigation and dryness with protaper paper points, obturation was performed using thermo-plasticized gutta-percha (DiaDent Group International, Seocho-dong, South Korea) and using resin-based sealer (Adseal, Metabiomed, Korea). All excess gutta-percha was removed from the pulp chamber as well as $1 \mathrm{~mm}$ below the orifice of each canal using carbide diamond bur (1014801-014-L2 19.0. Microdont, USA). Then, the canals were filled to the level of pulp chamber using flowable resin composite (Filtek Z350XT flowable, $3 \mathrm{M}$ ESPE, St Paul, MN, USA). The access cavity for each tooth was closed with temporary filling.

\section{Specimen fixation and periodontal simulation}

For artificial periodontal ligament of about 0.2$0.4 \mathrm{~mm}$ thick creation around the teeth, the roots of each molar were dipped into molten wax $2 \mathrm{~mm}$ apical to cemento-enamel junction to simulate bone level ${ }^{(16)}$. The obtained thin layer of wax simulates the average thickness of periodontal ligaments. Each tooth was mounted parallel to its long axis with its roots and embedded into a plastic mold filled with auto polymerizing resin (Acrostone; Acrostone dental factory, Industrial zone, Cairo, Egypt) till the level $2 \mathrm{~mm}$ apical to cemento-enamel junction. After the first signs of polymerization, the sample was removed from the resin and the wax spacer was eliminated by hot water. Then, the socket was injected with light consistency polyether impression material (Impregum ${ }^{\mathrm{TM}}$ Soft, 3M ESPE, USA) and the tooth was reinserted. Thus, a standardized silicon layer that simulated periodontal ligament was created ${ }^{(17)}$.

\section{Teeth Preparation for endocrowns}

Teeth preparation was done in accordance with the recommendation of Pissis ${ }^{(18)}$. For better control over reduction amount, silicon index was fabricated from hard duplication silicon material (Elite Double 22 Fast, Zhermack-Germany) for each tooth prior to reduction. After temporary restoration removal, 80 $\mu \mathrm{m}$ grit flat end tapered diamond bur (4137-856-025, Microdont, USA) mounted on high-speed handpiece was used to prepare a standardized central retention 
cavity that extends in the pulp chamber $6 \mathrm{~mm}$ deep from the central grooves and with $8^{\circ}$ divergent axial walls allowing removal of any axial undercuts.

Occlusal surfaces of all specimens were reduced by $2 \mathrm{~mm}$ in axial direction using diamond wheel bur (3054-024-21.0, Microdont, USA) to create a $360^{\circ}$ butt-joint surface. Complete flat surface was ensured by orienting the bur along the tooth long axis and parallel to the occlusal plane. All sharp internal line angles were smoothed and rounded with fine-grit $(30-40 \mu \mathrm{m})$ tapered diamond bur (4137F-856-025-L1 8.0-L2 21.0. Microdont, USA). All preparation was checked by a digital calliper; axial wall thickness of $2 \mathrm{~mm} \pm 0.2 \mathrm{~mm}$ was verified.

\section{Samples grouping}

The twenty-eight teeth samples were randomly divided into two groups $(n=14)$ to receive endocrowns using two CAD/CAM monolithic materials. These two materials were lithium disilicate (IPS E-max CAD) and resin hybrid ceramic (SHOFU Block HC) (Table1). Each group were subdivided into two equal subgroups $(\mathrm{n}=7)$ according to the type of test used in the study. These two tests were dynamic fatigue test and microleakage test. (Table 1)

\section{Endocrowns fabrication}

$\mathrm{CAD} / \mathrm{CAM}$ endocrown restorations were fabricated using CEREC AC system with Omnicam (Dentsply Sirona GmbH, Bensheim, Germany) (Figure 1). Omnicam intra oral scanner was used to scan all the prepared teeth. The CEREC 3D software (version 4.2, Sirona Dental Systems GmbH, Bensheim, Germany) was used for designing the endocrown restorations. Standardized restoration design with similar occlusal surface anatomy and occluso-gingival height was ensured for all endocrown restorations by using bio generic reference feature in CEREC software.

All restorations were milled with 4-axis wet milling and grinding machine MCXL (Dentsply Sirona, Bensheim, Germany). After milling is complete, sprues were cut and finished with diamond finishing stones. For LD group, the milled 14 specimens were crystallized and glazed in Programat P310 ceramic furnace (Ivoclar Vivadent Inc., New York, USA) following crystallization and glazing parameters provided by the manufacturer. While the specimens of SH group, the 14 milled specimens were finished and polished using Cera Master Kit (SHOFU Dental GmbH, Ratingen), Germany) according to manufacturer instructions. Finally, the occlusal and intracoronal thicknesses of all specimens were checked and verified using the digital caliper.

TABLE (1)

\begin{tabular}{|c|c|c|c|c|}
\hline Material & Manufacturer & Type & Composition & Lot NO. \\
\hline $\begin{array}{l}\text { IPS e.max } \\
\text { CAD } \\
\text { (LD) }\end{array}$ & $\begin{array}{l}\text { Ivoclar Vivadent Inc., } \\
\text { New York, USA }\end{array}$ & $\begin{array}{l}\text { Lithium } \\
\text { disilicate glass } \\
\text { ceramic }\end{array}$ & $\begin{array}{l}\text { Lithium disilicate-based glass-ceramic having } \\
\text { two phases: Partially crystallized phase consists } \\
\text { of } 40 \% \text { lithium metasilicate crystals embedded in } \\
\text { a glassy phase. Fully crystallized phase consists } \\
\text { of approximately } 70 \% \text { fine-grain lithium disilicate } \\
\text { crystals embedded in a glassy matrix. }\end{array}$ & Y52096 \\
\hline $\begin{array}{l}\text { Shofu Block } \\
\qquad \mathrm{HC} \\
(\mathrm{SH})\end{array}$ & $\begin{array}{l}\text { Dental GmbH, Ratingen, } \\
\text { Germany }\end{array}$ & $\begin{array}{l}\text { Composite } \\
\text { ceramic }\end{array}$ & $\begin{array}{l}\text { UDMA, TEGDMA, silica }(20 \mathrm{~nm}) \text {, barium glass } \\
(300 \mathrm{~nm}) \text {, silica powder, micro fumed silica, } \\
\text { zirconium silicate }\end{array}$ & 0818225 \\
\hline
\end{tabular}




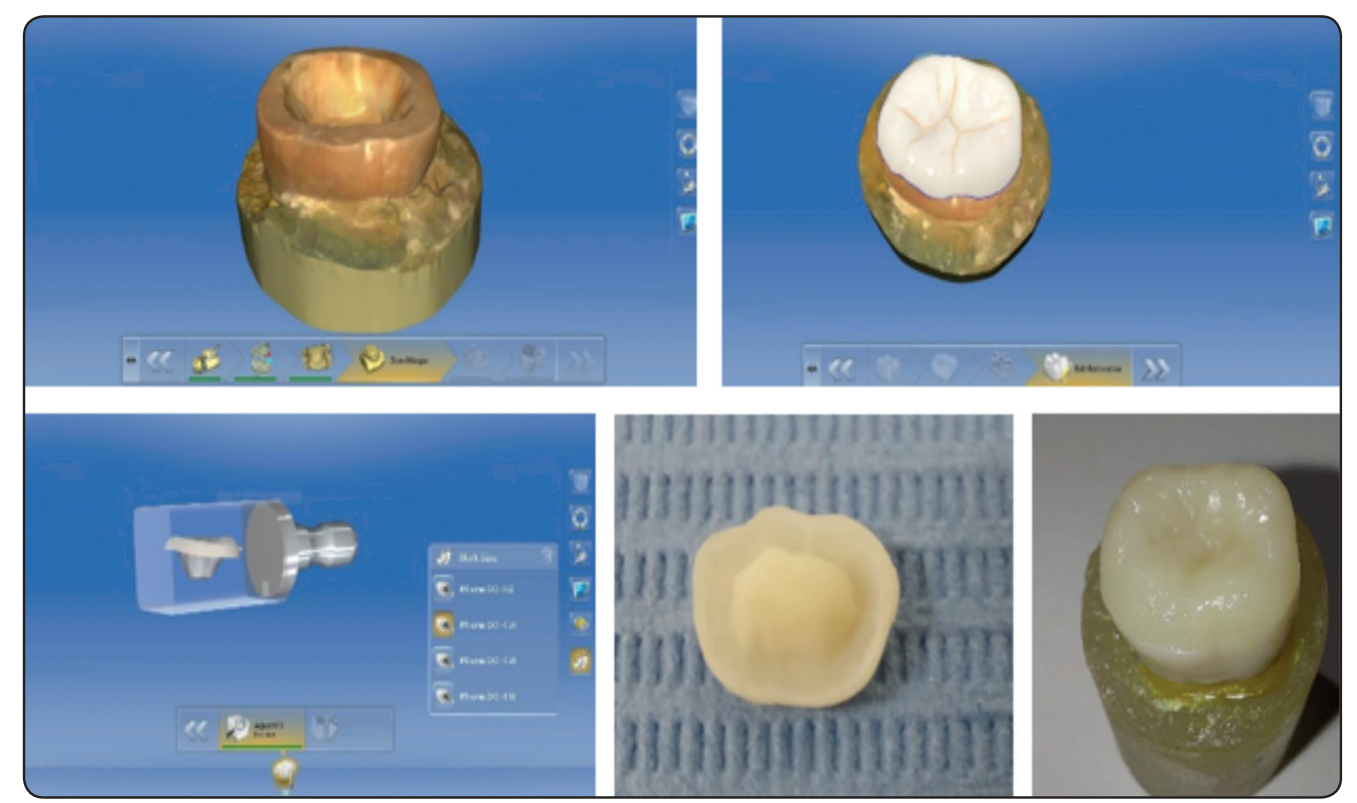

Fig. (1) Fabricated CAD/CAM endocrown restorations using CEREC AC system

\section{Bonding of endocrown samples}

All endocrown restorations were cleaned with 99\% isopropanol in an ultrasonic cleaner for 3 minutes, while the prepared teeth were cleaned for 15 seconds with fluoride-free pumice then rinsed thoroughly with water for 15 seconds.

The intaglio surface of each IPS e.max CAD (LD) restoration was etched with $9.5 \%$ hydrofluoric acid gel (Porcelain Etchant 9.5\%. BISCO, USA) for 60 seconds, then rinsed thoroughly and dried with oil free compressed air. Then, a silane coupling agent (Porcelain Primer Bis-silane, BISCO - USA) was applied for 60 seconds and air dried before cementation. For Shofu Block HC (SH) restorations, the intaglio surface was etched with $9.5 \%$ hydrofluoric acid gel for 30 seconds, rinsed then air dried, followed by application of special primer (HC Primer, SHOFU Dental, Ratingen, Germany) which was left for 30 seconds then air dried.

The prepared surfaces of all teeth samples were etched with $37 \%$ phosphoric acid etchant gel (Etch$37^{\mathrm{TM}}$. BISCO - USA) for 30 seconds, rinsed and air dried. Then, the surfaces were coated with two successive layers of bonding agent (All-Bond Universal. BISCO - USA) using a micro brush, thinned by air syringe, and light cured for 20 seconds.

All endocrowns were cemented to their corresponding teeth samples using dual-cured adhesive resin cement (Duolink dual cure selfetch resin cement. BISCO, USA) and $5 \mathrm{~kg}$ load was applied vertically by a specially designed loading device. After spot curing with light curing unit (Elipar $^{\mathrm{TM}}$, 3MESPE, USA), the excess cement was removed, then light curing was done for 40 seconds to each surface. All specimens were stored in distilled water at $37^{\circ} \mathrm{C}$ for 24 hours prior to thermal cycling.

\section{Thermocycling:}

All specimens were subjected to thermocycling in a water bath of a thermal cycling simulation device (Robota automated thermal cycle; BILGE, Turkey). The thermocycling was 5000 cycles, which are equivalent to 6 months, at $5^{\circ}$ and $55^{\circ} \mathrm{C}$. The dwell time in each water bath was 25 seconds with a lag time 10 seconds to simulate temperature fluctuations found in the oral cavity ${ }^{(19)}$. 


\section{Microleakage test:}

Seven samples from each group (LD) and (SH) were submitted to microleakage testing. Each sample was coated with two layers of nail polish except for $1 \mathrm{~mm}$ around the endocrown-tooth interface. All forty samples were immersed in an aqueous solution of $2 \%$ methylene blue dye (SD Fine-Chem limited, Mumbai, India) for $24 \mathrm{~h}$ at $37^{\circ} \mathrm{C}^{(20)}$. Then, the teeth were washed thoroughly under running water for 30 seconds. Each sample was mounted onto special holding device for sectioning in a buccolingual direction with a low-speed diamond saw (Top Dent, Edenta Golden, Rüthi, Switzerland) under water cooling. The sectioned specimens were washed and then dried with tissue paper. Using Stereomicroscope (Nikon Eclips E600, Tokyo, Japan), the dye penetration along the restorationtooth interface was assessed at $35 \times$ magnification in which the image of the restoration was captured and transferred to a computer equipped with the image analysis software program (Image J 1.43U, National Institute of Health, USA). Microleakage was assessed by measuring the dye penetration depth in ( $\mathrm{mm})$. For each tooth, dye penetration was calculated from the average of all readings of the two of both the buccal and the lingual margins.

\section{Fatigue resistance test (step-test method)}

The fatigue resistance test of each restorative material subgroup $(n=7)$ was evaluated through the modified dynamic technique (step-test method) on a computer-controlled testing machine (Model 3345; Instron Industrial Products, Norwood, USA) with a load cell of $5 \mathrm{kN}$. The data were recorded using computer software (Bluehill Lite; Instron Instruments) in a water filled chamber. Acrylic block of each sample was secured to the lower compartment of the testing machine. A compressive load was applied vertically on the occlusal surface of each sample using a metallic rod with spherical tip attached to the upper movable compartment of testing machine. The cyclic load was applied at a frequency of $1.6 \mathrm{~Hz}$ and a crosshead speed of $1 \mathrm{~mm} /$ minute with the maximum number of 5000 cycles at each load step. The step-test comprises that each specimen was subjected to a prescribed number of cycles at each of a sequence of increasing stress levels, until failure.

The step test for each sample was started by application of stress below the expected material fatigue strength until failure occurs. If failure did not occur and the specimen survived, the stress level is increased incrementally with a fixed load $(100 \mathrm{~N})$ and 5000 cycles at each load step. The procedure was continued until fracture of each specimen. An initial load of $260 \mathrm{~N}$ was applied, followed by successive steps of $100 \mathrm{~N}$. The software was adjusted to record the load and number of cycles required to fracture each sample. The maximum fatigue load $\left(\mathrm{L}_{\mathrm{E}}\right)$ supported by each specimen was calculated according to the equation represented by Nicholas ${ }^{(21)}$ :

$$
\mathrm{L}_{\mathrm{E}}=\mathrm{L}_{0}+\Delta \mathrm{L} \quad\left(\frac{\mathrm{N}_{\text {fail }}}{\mathrm{N}_{\text {life }}}\right)
$$

Where: $\mathrm{L}_{0}=$ The previous maximum fatigue load which did not cause failure,

$\Delta \mathrm{L}=$ The load step increase, $\mathrm{N}_{\text {fail }}=$ Number of cycles till failure $\left(\mathrm{L}_{0}+\mathrm{L}_{\mathrm{E}}\right)$,

$\mathrm{N}_{\text {life }}=$ The defined cyclic fatigue life (5000 cycles).

\section{Statistical analysis:}

Data from the two groups were collected, arranged using Excel for Microsoft (version 365). The data obtained using the dynamic fatigue failure load cycles, and survival table to compare fatigue failure of the groups. Student t-test was used to verify statistical difference between both groups. Correlation between leakage and dynamic fatigue failure was found by Pearson linear correlation. Statistical analysis was performed using Graph-Pad Instat statistics software (version 3.06) for Windows. $P$ values $<0.05$ were statistically significant in all tests. Sample size ( $n=7 /$ subgroup) was large enough to detect large effect sizes for main effects and pairwise comparisons, with the satisfactory level of power set at $80 \%$ and a $95 \%$ confidence level. 


\section{RESULTS}

\section{Dynamic fatigue failure}

Descriptive statistics showing mean values and standard deviation of dynamic fatigue failure load test results measured by step-stress method (Newton) for both groups are shown in Table (2). It was found that Shofu HC (SH) group recorded higher mean \pm SD value of dynamic fatigue failure load (1005.02 \pm $100.25 \mathrm{~N})$ than IPS e.max CAD (LD) group mean $\pm \mathrm{SD}$ value $(881.76 \pm 52.39 \mathrm{~N})$. The difference between both groups was statistically significant as indicated by student t-test $(\mathrm{P}=0.0138<0.05)$.

Regarding fatigue failure cycles, it was found that $\mathrm{SH}$ group recorded higher mean $\pm \mathrm{SD}$ value of dynamic fatigue failure cycles (41001 3196 cycles) than LD group mean \pm SD value $(36088 \pm$ 2619 cycles). The difference between both groups was statistically significant as indicated by student t-test $(\mathrm{P}=0.008<0.05)$ as shown in Table (3).

The survival performance for SH group was better than LD group as summarized in (Table 4) and graphically drawn (Figure 2).

TABLE (2): Comparison of dynamic fatigue failure load results (Mean values \pm SDs) as function of a group

\begin{tabular}{|c|c|c|c|c|c|c|}
\hline \multirow{2}{*}{\multicolumn{2}{|c|}{ Variables }} & \multirow{3}{*}{$\begin{array}{c}\text { Mean } \pm \text { SDs } \\
\mathbf{8 8 1 . 7 6} \pm \mathbf{5 2 . 3 9}\end{array}$} & \multicolumn{2}{|c|}{$95 \% \mathrm{CI}$} & \multirow{2}{*}{\multicolumn{2}{|c|}{ Statistics }} \\
\hline & & & \multirow{2}{*}{$\frac{\text { Low }}{833.3}$} & \multirow{2}{*}{$\begin{array}{c}\text { High } \\
930.22\end{array}$} & & \\
\hline \multirow{2}{*}{ Group } & LD & & & & t value & $P$ value \\
\hline & SH & $1005.02 \pm 100.25$ & 912.29 & 1097.7 & 2.9 & $0.0138 *$ \\
\hline
\end{tabular}

*; significant $(p<0.05) \quad N S$; non-significant $(p>0.05)$

TABLE (3): Comparison of dynamic fatigue failure cycles results (Mean values \pm SDs) as function of a group

\begin{tabular}{llcccccc}
\hline \multirow{2}{*}{ Variables } & & \multirow{2}{*}{ Mean \pm SDs } & \multicolumn{2}{c}{ 95\% CI } & & \multicolumn{2}{c}{ Statistics } \\
\cline { 5 - 6 } & & & Low & High & & \\
\hline \multirow{2}{*}{ Group } & LD & $\mathbf{3 6 0 8 8} \pm \mathbf{2 6 1 9}$ & 33665 & 38511 & t value & P value \\
& SH & $\mathbf{4 1 0 0 1 \pm \mathbf { 3 1 9 6 }}$ & 38044 & 43975 & 3.14 & $0.008^{*}$ \\
\hline
\end{tabular}

*; significant $(p<0.05)$

NS; non-significant ( $p>0.05)$

TABLE (4): Survival rate of samples recorded for both experimental groups at different step load.

\begin{tabular}{lccc}
\hline & \multicolumn{2}{c}{ Group } \\
\cline { 3 - 4 } & & LD & SH \\
\hline \multirow{4}{*}{ Step } & $260 \mathrm{~N}$ & 7 & 7 \\
& $360 \mathrm{~N}$ & 7 & 7 \\
& $460 \mathrm{~N}$ & 7 & 7 \\
& $560 \mathrm{~N}$ & 7 & 7 \\
& $660 \mathrm{~N}$ & 7 & 7 \\
& $760 \mathrm{~N}$ & 7 & 7 \\
& $860 \mathrm{~N}$ & 4 & 7 \\
& $960 \mathrm{~N}$ & 2 & 4 \\
& $1060 \mathrm{~N}$ & 1 & 2 \\
& $1160 \mathrm{~N}$ & 0 & 1 \\
& $1260 \mathrm{~N}$ & 0 & 0 \\
\hline
\end{tabular}

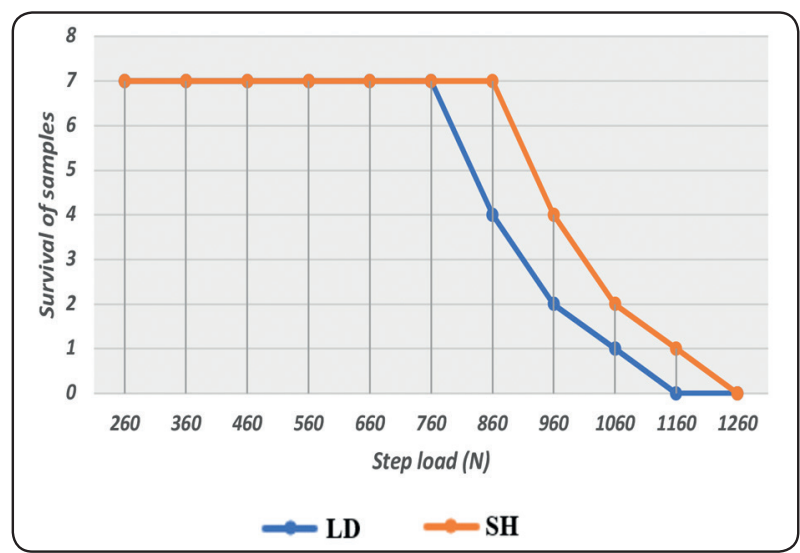

Fig. (2): Linear curves showing survival rate of samples recorded for both experimental groups 


\section{Microleakage:}

Descriptive statistics showing mean values and standard deviation of microleakage test results measured by dye penetration $(\mu \mathrm{m})$ for both groups after aging are shown in Table (5). It was found that LD group recorded higher mean \pm SD value of leakage $(122.87 \pm 15.84 \mu \mathrm{m})$ than $\mathrm{SH}$ group mean $\pm \mathrm{SD}$ value $(102.04 \pm 11.20 \mu \mathrm{m})$. The difference between both groups was statistically significant as indicated by student t-test $(\mathrm{P}=0.0149<0.05)$.

\section{Correlation between leakage and dynamic fa- tigue failure load:}

It was found that there was an inverse correlation between microleakage and dynamic fatigue failure load of the tested groups (Figure 3) as indicated by Pearson linear correlation (Correlation coefficient $(r)=-0.4484, r^{2}=0.2010$ and $\left.p=0.313>0.05\right)$

TABLE (5): Comparison of microleakage results (Mean values \pm SDs) as function of a group

\begin{tabular}{llccccc}
\hline \multirow{2}{*}{ Variables } & & \multirow{2}{*}{ Mean \pm SDs } & \multicolumn{2}{c}{$\mathbf{9 5 \%}$ CI } & \multicolumn{2}{c}{ Statistics } \\
\cline { 5 - 6 } & & & Low & High & & \\
\hline \multirow{2}{*}{ Group } & LD & $\mathbf{1 2 2 . 8 7} \pm \mathbf{1 5 . 8 4}$ & 108.22 & 137.53 & t value & P value \\
& SH & $\mathbf{1 0 2 . 0 4 \pm \mathbf { 1 1 . 2 0 }}$ & 91.68 & 112.41 & 2.8 & $0.0149^{*}$ \\
\hline
\end{tabular}

*; significant $(p<0.05)$

NS; non-significant ( $p>0.05$

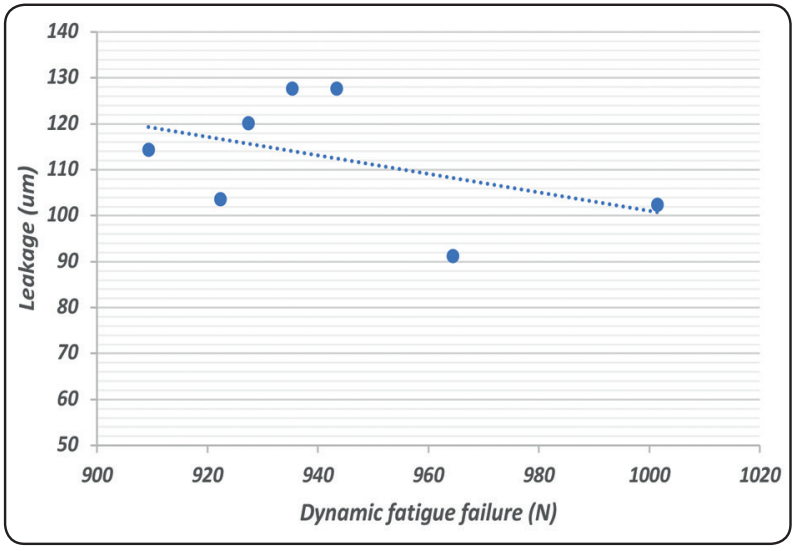

Fig. (3): Linear chart showing correlation between microleakage and dynamic fatigue failure load

\section{DISCUSSION}

Endocrown is a more conservative coronal restorative modality of the endodontically treated teeth, which can provide optimum esthetics as well as protection of the remaining tooth from fracture and biomechanical failure. The material used for endocrown fabrication should have a modulus of elasticity similar to the dentin to allow proper distribution of occlusal forces and possibly increases the fracture resistance ${ }^{(22)}$. Moreover, the material should have a high mechanical strength and high bond strength to the underlying remaining tooth structure ${ }^{(23)}$.

The aim of this in vitro study was to investigate the effect of two monolithic CAD/CAM ceramic materials on the fracture resistance of endocrowns subjected to dynamic fatigue loading. Also, the effect of surface pre-treatments of each material on microleakage was studied. The results revealed that the shofu resin hybrid ceramic endocrowns had superior fatigue resistance and lower microleakage 
than IPS e-max CAD lithium disilicate-based ceramics and therefore, the null hypothesis was rejected.

In this study, Shofu Block HC material was selected as a new type of CAD/CAM material that combines the benefits of both ceramic and composite materials. Also, IPS e-max CAD lithium disilicate ceramic was chosen for comparison, as this material was used in most in-vitro studies for endocrown fabrications $(5,6,24,25)$. The selected occlusal thickness of endocrown restorations was $2.0 \mathrm{~mm}$ as the minimum thickness of $1.5 \mathrm{~mm}$ offered acceptable survival and fracture load if adhesion is respected ${ }^{(25,26)}$. The applied cyclic load was at a frequency of $1.6 \mathrm{~Hz}$ which could simulate the clinical oral masticatory conditions ${ }^{(5)}$.

The result of this study showed a significant mean dynamic fatigue failure load value for Shofu $\mathrm{HC}$ resin hybrid ceramic endocrown group higher than that lithium disilicate ceramic group. This result agreed with those of Furtado de Mendonça et $\mathrm{al}^{(27)}$ who studied the microstructural and mechanical characterization of monolithic $\mathrm{CAD} /$ CAM restorations. They stated that the higher flexibility, lower stiffness, and acceptable flexural strength of resin hybrid ceramics make these materials suitable for chairside monolithic crown fabrication. These results were also in agreement with Venturini et al, ${ }^{(28)}$ they explained that while the load increases, the resin ceramic restoration is vulnerable to deformation before failure, which may modify surface contact area and stress distribution through the restored tooth.

Shofu HC is a CAD/CAM resin hybrid ceramic which is high temperature polymerized. This high temperature post-cure treatment is applied to reduce polymerization shrinkage of the material and provides modulus of elasticity close to dentine resulting in lower brittleness and lower catastrophic failures compared to the rigid lithium disilicate ceramics ${ }^{(29,30)}$.
Despite the lower flexural strength of Shofu HC resin hybrid ceramic compared to IPS emax CAD lithium disilicates ceramic, Shofu HC survival performance was better in terms of dynamic fatigue load and number of cycles till failure. This investigation might explain that $\mathrm{SH}$ has better damage tolerance than lithium disilicate.

In this study, microleakage test was performed using methylene blue dye in order to obtain results that is consistent with the clinical situations. Consequently, if the restoration samples showed less microleakage in vitro, they would likely achieve a proper clinical performance ${ }^{(31)}$.

Adhesive bonding of endocrown restoration is considered one of the most important factors contributing for long-term success clinically ${ }^{(14)}$. There are many surface pretreatment protocols proposed for bonding each ceramic restoration according to its chemical compositions. Lithium disilicate is an etchable ceramic which can be etched with hydrofluoric acid to create micro-pores and grooves resulting in an appropriate microstructure for micromechanical bonding to resin cement. Ang and Tew ${ }^{(25)}$ indicated that $\mathrm{HC}$ primer application on the bonding surface of endocrown made of hybrid ceramic improved the bond strength to the resin cement leading to limited microleakage. HC primer contains urethane dimethacrylate, methyl methacrylate, and acetone, which might enable it to penetrate the hybrid-ceramic matrix ${ }^{(31)}$. Also, using a dualcure resin cement might enhance a good chemical bonding for either hybrid-ceramic restoration or tooth substructure ${ }^{(33)}$. Furthermore, milling of resin-hybrid CAD/CAM endocrowns results in more accurate margins with less flaws and irregularities than e-max CAD. These regular marginal adaptations could decrease microleakage.

The greater dynamic fatigue fracture strength of Shofu HC observed in the present study might be due to the higher bonding mechanism, which could explain the inverse correlation between microleakage and dynamic fatigue failure load of both tested materials ${ }^{(34)}$. 
One of the limitations of the present study was the direction of dynamic fatigue load application. In clinical conditions, fractures caused by cyclic loading usually occurs in multiple directions. In this study, samples were only subjected to compressive and axial loading only. Moreover, artificial saliva was not utilized in this study and thermocycling was limited to 5000 cycles which can be considered as another limitation. Further studies are required to investigate these limitations.

\section{CONCLUSIONS}

Based on the results of this study, it was concluded that:

- Endocrowns made of Shofu HC resin-hybrid ceramic showed higher biomechanical behavior in terms dynamic fatigue failure load and number of cycles until failure compared with that made of lithium disilicate IPS e.max CAD glass ceramic.

- Microleakage of Shofu HC resin-hybrid ceramic endocrowns was less than that of lithium disilicate glass-ceramic endocrowns.

- Shofu HC Hybrid CAD/CAM ceramic material can be considered as a promising alternative to lithium disilicate ceramic material for fabrication of endocrown restorations. However, further clinical studies are required to support these results.

\section{REFERENCES}

1. Al-Dabbagh RA. Survival and success of endocrowns: A systematic review and meta-analysis. J Prosthet Dent. 2021 Mar;125(3): 415.e1-415.

2. Bindl A, Mormann WH. Clinical evaluation of adhesively placed cerec endocrowns after 2 years-preliminary results. J Adhes Dent. 1999; 1:255-65.

3. Magne P, Knezevic A. Simulated fatigue resistance of composite resin versus porcelain CAD/CAM overlay restorations on endodontically treated molars. Quintessence Int 2009; 40:125-33.
4. Alamoush, R.; Silikas, N.; Salim, N.; Al-Nasrawi, S.; Satterthwaite, J.D. Eect of the composition of CAD/CAM composite blocks on mechanical properties. BioMed Res Int 2018, 2018, 4893143 .

5. Dartora G, Rocha Pereira GK, Varella de Carvalho R, Zucuni CP, Valandro LF, Cesar PF, Caldas RA, Bacchi A. Comparison of endocrowns made of lithium disilicate glass-ceramic or polymer-infiltrated ceramic networks and direct composite resin restorations: fatigue performance and stress distribution. J Mech Behav Biomed Mater. 2019;100: 103401 .

6. Elashmawy Y, Elshahawy W, Seddik M, Aboushelib M. Influence of fatigue loading on fracture resistance of endodontically treated teeth restored with endocrowns. J Prosthodont Res. 2020 Sep 9.

7. Papadopoulos K, Pahinis K, Saltidou K, Dionysopoulos D, Tsitrou E. Evaluation of the Surface Characteristics of Dental CAD/CAM Materials after Different Surface Treatments. Materials (Basel). 2020 Feb 22;13(4):981

8. Kelly JR, Benetti P. Ceramic materials in dentistry: historical evolution and current practice. Aust Dent J 2011; 56:84-96.

9. Mainjot A. Recent advances in composite CAD/CAM blocks. Int J Esthet Dent. 2016;11(2):275-80.

10. Ruse, N.D.; Sadoun, M.J. Resin-composite blocks for dental CAD/CAM applications. J. Dent. Res. 2014, 93, $1232-1234$.

11. Coldea, A.; Swain, M.V.; Thiel, N. Mechanical properties of polymer-infiltrated-ceramic-network materials. Dent. Mater. 2013, 29, 419-426.

12. Spitznagel, F.A.; Boldt, J.; Gierthmuehlen, P.C. CAD/ CAM ceramic restorative materials for natural teeth. J. Dent. Res. 2018, 97, 1082-1091.

13. El Zohairy AA, De Gee AJ, Mohsen MM, Feilzer AJ. Microtensile bond strength testing of luting cements to prefabricated CAD/CAM ceramic and composite blocks. Dent Mater. 2003; 19: 575-83.

14. Frankenberger R, Lohbauer U, Taschner M, Petschelt A, Nikolaenko SA. Adhesive luting revisited: influence of adhesive, temporary cement, cavity cleaning, and curing mode on internal dentin bond strength. J Adhes Dent. 2007; 9: 269-73

15. Shin, Y.; Park, S.; Park, J.W.; Kim, K.M.; Park, Y.B.; Roh, B.D. Evaluation of the marginal and internal discrepancies 
of CAD-CAM endocrowns with different cavity depths: An in vitro study. J. Prosthet. Dent. 2016; 117: 109-15.

16. El-Damanhoury HM, Haj-Ali RN, Platt JA. Fracture resistance and microleakage of endocrowns utilizing three CAD-CAM blocks. Oper Dent. 2015; 40: 201-10.

17. Aboushelib MN, Elsafi MH. Survival of resin infiltrated ceramics under influence of fatigue. Dent Mater. 2016; 32: 529-34.

18. Pissis P. Fabrication of a metal-free ceramic restoration utilizing the monobloc technique. Pract Periodontics Aesthet Dent. 1995;7(5): 83-94.

19. Morresi AL, D'Amario M, Capogreco M, Gatto R, Marzo G, D'Arcangelo C, Monaco A. Thermal cycling for restorative materials: Does a standardized protocol exist in laboratory testing? A literature review. J Mech Behav Biomed Mater. 2014; 29: 295-308.

20. Abo-Elmagd,A.A.; Abdel-Aziz, M. Influence of marginal preparation design on microleakage and marginal gap of endocrown cemented with adhesive resin cement. Egypt Dent. J. 2015; 61: 5481-9.

21. Nicholas T. Accelerated test techniques. In: High cyclefatigue: a mechanics of materials perspective. Oxford: Elsevier Ltd; 2006. p. 70-134.

22. Tang W, Wu Y, Smales RJ. Identifying and reducing risks for potential fractures in endodontically treated teeth. J Endod. 2010; 36: 609-17.

23. Zhu J, Rong Q, Wang X, Gao X. Influence of remaining tooth structure and restorative material type on stress distribution in endodontically treated maxillary premolars: a finite element analysis. J Prosthet Dent. 2017; 117: 646-55.

24. Hasanzade M, Moharrami M, Alikhasi M. Evaluation of Marginal and Internal Adaptation of Endocrowns Fabricated from Three Different CAD/CAM Materials. Eur J Prosthodont Restor Dent. 2019; 27(4):164-71.

25. Ang Y, Tew IM. Conservative management of extensively damaged endodontically treated tooth using computeraided design and computer-aided manufacturing-based hybrid-ceramic endocrown: A clinical report. J Conserv Dent. 2020; 23(6): 644-7.

26. Tribst J, Piva A1, Madruga C, Valera M, et al. The impact of restorative material and ceramic thickness on CAD\CAM endocrowns. J Clin Exp Dent. 2019; 11(11): e969-77.

27. Furtado de Mendonça, A., Shahmoradi, M., Gouvêa, C.V.D., De Souza, G.M., Ellakwa, A. Microstructural and mechanical characterization of CAD/CAM materials for monolithic dental restorations. J. Prosthodont. 2019; 28: 587-94.

28. Venturini, A.B., Prochnow, C., Pereira, G.K.R., Segala, R.D., Kleverlaan, C.J., Valandro, L.F. Fatigue performance of adhesively cemented glass-, hybrid- and resin ceramic materials for CAD/CAM monolithic restorations. 2019; Dent. Mater. 35: 534-42.

29. A.K. Mainjot, N.M. Dupont, J.C. Oudkerk, T.Y. Dewael, M.J. Sadoun, From Artisanal to CAD-CAM Blocks: State of the Art of Indirect Composites, J. Dent. Res. 2016; 95(5): 487- 95.

30. Altier M, Erol F, Yildirim G, Dalkilic EE. Fracture resistance and failure modes of lithium disilicate or composite endocrowns. Niger J Clin Pract. 2018; 21(7):821-6.

31. Pashley DH. Clinical considerations of microleakage. J Endod. 1990;16(2):70-7.

32. Hagino R, Mine A, Kawaguchi-Uemura A, Tajiri Y, Yumitate $\mathrm{M}$, Ban $\mathrm{S}$, et al. Adhesion procedures for CAD/CAM indirect resin composite block: A new resin primer versus a conventional silanizing agent. J Prosthodont Res. 2020; 64: 319-25.

33. Turp V, Sen D, Tuncelli B, Ozcan M. Adhesion of 10MDP containing resin cements to dentin with and without the etchand-rinse technique. J Adv Prosthodont. 2013; 5: 226-33.

34. Jassim ZM, Majeed MA. Comparative evaluation of the fracture strength of monolithic crowns fabricated from different all-ceramic CAD/CAM materials (an in vitro study). Biomed Pharmacol J. 2018; 11:1689-97 